\title{
Analysis of 92 mitral pulmonary autograft replacement (Ross II) operations
}

\author{
Sami Kabbani, MD, Hisham Jamil, MD, Fawzi Nabhani, MD, Abdo Hamoud, MD, Karam Katan, MD, Nada Sabbagh, MD, \\ Abir Koudsi, PhD, MD, Loay Kabbani, MD, and Ghiath Hamed, MD
}

Supplemental material is available online.
From the Damascus University Cardiovascular Surgical Center, Mezza, Damascus, Syria.

Read at the Eighty-sixth Annual Meeting of The American Association for Thoracic Surgery, Philadelphia, Pa, April 29-May 3, 2006.

Received for publication May 29, 2006; revisions received April 29, 2007; accepted for publication May 11, 2007.

Address for reprints: Sami Kabbani, MD, Damascus University Cardiovascular Surgical Center, Mezza Str, PO Box 2837, Damascus, Syria (E-mail: dam-uncv@net.sy).

J Thorac Cardiovasc Surg 2007;134:902-8

$0022-5223 / \$ 32.00$

Copyright $\odot 2007$ by The American Association for Thoracic Surgery

doi:10.1016/j.jtcvs.2007.05.056
Objective: The study objective was to find a mitral valve substitute that does not require lifelong anticoagulation and is not affected by tissue degeneration in the long term.

Methods: Between July 14, 1997, and August 8, 2004, a total of 92 patients with irreparable mitral valve disease underwent mitral valve replacement with the pulmonary autograft encased within a Dacron tubing for support. In 4 patients, the autograft had to be sacrificed at the initial operation. Of the remaining 88 patients, 62 were female, and the age ranged from 4 to 64 years (mean 39 years). Eighty-six patients had rheumatic mitral disease, and 2 patients had congenital mitral disease.

Results: Operative transesophageal echocardiography initially showed adequate valve characteristics (mean valve area $2.8 \mathrm{~cm}^{2}$, mean gradient $3.9 \mathrm{~mm} \mathrm{Hg}$, no significant regurgitation) in all 88 patients. Operative mortality was $4.6 \%$, and late mortality definitely related to the operation was $7.9 \%$. Four patients were lost to follow-up; the mean follow-up was 60 months. Progressive regurgitation and stenosis developed in 9 patients over 2 to 5 years, 4 of whom had their grafts explanted. The autograft was explanted in 1 patient because of endocarditis. Mild pulmonic stenosis developed in 3 patients, and critical pulmonic stenosis developed in 1 patient. At 5 years follow-up, freedom from degeneration was $93.4 \%$, freedom from reoperation was $94.2 \%$, and freedom from all death was $86.0 \%$.

Conclusion: Although the Ross II operation is difficult and harbors significant risk, it remains an option for patients with irreparable mitral disease who have a long life expectancy and who cannot be placed on lifelong anticoagulation.

I $\mathrm{n}$ an effort to find an optimal mitral valve substitute for patients with rheumatic mitral disease that does not require the lifelong anticoagulation necessary for mechanical valves and resists the expected outcome of degeneration of heterograft and homograft valves, we started to revive the Ross concept of substituting the inverted pulmonary autograft for the excised mitral valve in $1997 .{ }^{1}$ In this endeavor we hoped to achieve for the mitral valve what has already been accomplished for the aortic valve. ${ }^{2}$ This study is an analysis of the outcome of 92 pulmonary autografts implanted in the mitral position during a 7 -year period, ending in August of 2004.

\section{Materials and Methods}

Between July 14, 1997, and August 8, 2004, a total of 92 consecutive patients with irreparable mitral valve disease underwent mitral valve replacement with the pulmonary autograft (Ross II operation) by the same surgical team at Damascus University Cardiovascular Surgical Center.

Because of a temporary lack of pulmonary homografts and xenografts, as well as a precipitous decrease in available mitral candidates, we were unable to perform this procedure for approximately 8 months after August 8, 2004. After this date, the operation was resumed 


\section{Abbreviation and Acronym}

$\mathrm{TEE}=$ transesophageal echocardiography

on a sporadic basis as allowed by patients' availability. In this report we present the analysis of our first 92 patients, because they belonged to a single time frame.

Exclusion criteria were significant aortic valve disease, pulmonary artery systolic pressure greater than $90 \mathrm{~mm} \mathrm{Hg}$, previous cardiac operation or pericardial adhesions found at operation, annular mitral calcification, and ejection fraction less than $30 \%$.

The mitral pulmonary autograft had to be sacrificed during the initial operation in 4 of the 92 patients, so the total number of patients reviewed was 88 .

The male-to-female ratio was 26:62, and the patients were aged between 4 and 64 years, with a mean of 39.2 years ( \pm 11.2 years). Figure E1 depicts the age distribution according to 10-year groups.

Eighty-six patients had rheumatic mitral disease, and 2 patients had congenital mitral lesions (a parachute mitral valve in 1 patient and bileaflet mitral prolapse in 1 patient). Thirty-five patients had predominant mitral stenosis, 42 patients had combined mitral stenosis and regurgitation, and 11 patients had pure mitral regurgitation. Twenty-six patients had, in addition, significant degrees $(\geq 2 / 4)$ of tricuspid regurgitation, and 41 patients had insignificant $(<1.5 / 4)$ aortic regurgitation. Fifty patients were in atrial fibrillation, and 38 patients were in sinus rhythm. Twenty-eight patients underwent cardiac catheterization to rule out coronary artery disease. Most patients (81) were in New York Heart Association classes II and III, and preoperative echocardiography showed a mean left atrial size of $6.0 \mathrm{~cm}$. Table E1 shows some of the preoperative echo/Doppler data.

Every effort was made to repair the mitral valve before a decision on the operation was made. Carpentier's principles of mitral repair ${ }^{3}$ were strictly adhered to. The ratio of patients actually undergoing the Ross II procedure to those undergoing the operation with the intent of performing it in case the mitral valve was found irreparable was 1 to 3 .

Details of the operation were described in a previous report. ${ }^{4}$ The operation in principle involves encasing the pulmonary autograft within a Dacron tubing of appropriate size for support before suturing its distal (pulmonary) end to the excised mitral valve annulus.

All operations were conducted under cardiopulmonary bypass, moderate hypothermia, and blood cardioplegia. In the early stages of our experience we favored a transseptal approach, but lately we have relied on a standard left atriotomy, except when the left atrium is small $(<5 \mathrm{~cm})$.

Once the mitral valve was found beyond repair and a decision was made to operate, the pulmonary artery was taken down and replaced with a suitable tissue substitute, as in the classic Ross operation. Twenty-nine cryopreserved pulmonary homografts, 56 pulmonary xenografts (Ross, CryoLife, Inc, Kennesaw, Ga), and 3 cryopreserved aortic homografts were used for pulmonary trunk replacement.

While the surgeon replaced the pulmonary artery, the cosurgeon inserted the trimmed pulmonary autograft inside a piece of rigid Dacron tubing and sewed the proximal and distal ends to the tubing edges, guided by premarked lines. The size of the Dacron tubing was chosen to be slightly larger than the eye-balled size of the pulmonary artery (a 1-inch long piece of size 30-mm tubing was used in most patients). In the 2 children with congenital mitral lesions, the tubing was slit (along 1 side in 1 patient and along 2 sides in 1 patient) to allow for mitral annular growth with the growth of the child. The mitral valve was excised, preserving as much of the native subvalvular apparatus as possible, and the left atrial appendage was excluded.

Since December of 2002, microwave ablation (AFx, Inc, Fremont, Calif) has been used in all of our patients with mitral disease and atrial fibrillation. ${ }^{5}$ Eleven patients in this series had atrial fibrillation ablation. The distal end of the autograft/Dacron conduit was finally sutured to the mitral annulus, the tricuspid valve was repaired if necessary, and the atriotomy was closed. Intraoperative transesophageal echocardiography (TEE) was obtained when the heart resumed its activity to ensure that results were acceptable before decannulation and chest closure.

We chose to place the pulmonary autograft conduit in the atrium rather than the ventricle because the design of the inverted pulmonary autograft does not lend itself to having its distal (pulmonary truck) end sutured to the papillary muscles, as is the case with the mitral homograft. Further, if most of the autograft/Dacron tubing is placed in the ventricle it is bound to cause some left ventricular outflow obstruction, as was found in the early experiments replacing the mitral valve with the pulmonary-autograft or aortic homograft, before Hubka ${ }^{6}$ introduced the concept of placing the conduit completely in the left atrium.

The "Achilles heel" of this operation has been conduit obstruction in some patients because of the angulation of the soft tubing material, necessitating immediate reoperation for correction or re-replacement. This potential problem has been managed in a variety of ways over the years. ${ }^{7-9}$

In the first 36 patients, a pericardial patch was used to anchor the proximal edge of the autograft/Dacron conduit to the adjacent atrial wall ("top-hat" configuration), at the same time covering foreign material and creating, in essence, a new left atrial floor, a method originally advocated by Yacoub and Kittle. ${ }^{10}$ Because this method did not seem to prevent Dacron tubing collapse, as we accidentally found out, and it became obvious to us that the firmness of the Dacron material played a major role in preventing the iatrogenic atrioventricular obstruction, we began using pericardium simply to cover foreign material as a "miniskirt" to save operative time and decrease operative risk. ${ }^{4} \mathrm{We}$ also avoided modern soft varieties of Dacron and adhered to using the original resilient Dacron tissue when it was available, or autoclaving the soft varieties with albumin when it was not, to give them the required resilience. After 10 patients we abandoned the use of pericardium altogether to simplify the operation even further. Finally, because we were having difficulty obtaining old-fashioned Dacron tubings, and because there was kinking of the Dacron tubing even after autoclave treatment with albumin in 2 patients (possibly because the albumin coating dissolved later in warm blood), we returned to the "miniskirt" pericardial configuration.

We now use the "miniskirt" pericardial configuration ${ }^{4}$ using surgical glue (Bio Glue, CryoLife Inc, Kennesaw, Ga) in between the Dacron cloth and the pericardial tissue. This seems to give the 
conduit the firm texture required and has solved the potential problem of mitral obstruction.

Table E2 shows the details of the operation in this series. Figure $\mathrm{E} 2, A$ to $O$, depicts the various stages of the operation as we now perform it. Figure E3 shows the Dacron conduit in a postoperative 4-chamber view echocardiogram and a typical 2-dimensional echocardiogram with color Doppler.

Follow-up with echocardiography was scheduled 1, 3, and 6 months after the operation and yearly afterward. Patients were anticoagulated for 3 months after the procedure, after which the anticoagulant was discontinued, except for those patients who remained in atrial fibrillation and an international normalized ratio of 2 to 2.5 was sought. It has also been our policy to administer penicillin prophylaxis at least until the patient is 40 years old.

Analyses were performed with Intercooled STATA version 9 (StataCorp, College Station, Tex) and the Statistical Package for the Social Sciences version 14 (SPSS Inc, Chicago, Ill). Survival curves were done using Kaplan-Meier in the Statistical Package for the Social Sciences version 14 (SPSS Inc). Autograft degeneration was designated as such when the mitral valve area was less than $1.5 \mathrm{~cm}^{2}$ and/or when regurgitation was more than $1.5 / 4$ (1.5 corresponding to mild regurgitation). The mitral regurgitation was estimated by jet size and mental 3-dimensional jet reconstruction.

\section{Results}

Intraoperative TEE showed acceptable-to-excellent valve areas (1.9-4.5 $\mathrm{cm}^{2}$; mean $\left.2.76 \pm 0.45\right)$ and gradients (1.5-9 mm; mean $2.86 \pm 0.6)$, and 0 -trace mitral regurgitation $(<1.5 / 4)$ in 86 patients. However, in 6 of the total 92 patients, starting with our 33 rd case, a significant obstruction was detected by intraoperative TEE, which was caused by the shift from using old-fashioned Dacron tubing material to using modern soft tubing material. In 2 of these patients the problem was corrected at reexploration, ${ }^{7}$ but in 4 patients the autograft had to be explanted and replaced with a mechanical valve (bioprostheses were not available at our unit at the time). All 4 patients who underwent re-replacement of the autograft with mechanical prostheses are presently well. The problem of acute autograft stenosis was resolved with the use of surgical glue between the Dacron cloth and the pericardial wrap and has not recurred in our last 42 patients. Atrial fibrillation spontaneously changed to sinus rhythm postoperatively in 10 patients, and of 11 patients who had microwave ablation, 8 were successfully converted to sinus rhythm.

Hospital mortality was $4.5 \%$ (4 patients). Table 1 lists the causes of mortality and major hospital events. The median intensive care unit stay was 2 days, and the median hospital stay was 7 days. There was 1 major hospital wound infection. The estimated pulmonary artery pressure on discharge from the hospital was 12 to $60 \mathrm{~mm} \mathrm{Hg}$ with a mean of $27.4 \pm 9.5$. Table E3 shows the echo/Doppler findings on discharge from the hospital, which mimicked the findings of intraoperative TEE.
TABLE 1. Mortality and hospital events

\begin{tabular}{lc}
\hline & No. of patients \\
\hline Mortality & $4 / 88(4.5 \%)$ \\
CVA & 1 \\
ARDS & 1 \\
Bleeding & 1 \\
Acute renal failure & 1 \\
Hospital event & 2 (1 requiring IABP) \\
MI & 1 (requiring IABP) \\
Low CO & 3 \\
Bleeding & 5 \\
AV dissociation (temporary) & 3 \\
AF (temporary) & 3 \\
PPS & 3 \\
Paravalvular leak (minor) & 1 \\
Repair of flail pericardial collar & \\
\hline
\end{tabular}

CVA, Cerebrovascular accident; $A R D S$, acute respiratory distress syndrome; $M I$, myocardial infarction; $I A B P$, intraaortic balloon pumping; $C O$, cardiac output; $A V$, atrioventricular; $A F$, atrial fibrillation; PPS, post-pericardiotomy syndrome.

Four patients were lost to follow-up because of change of address. The mean follow-up period was 60 months. Late mortality totaled 11 patients. Two died of early endocarditis (within 2 months of operation) suspected to have originated from nosocomial attacks that affected our unit at the same period their operations were performed. One patient died of bleeding at reoperation for paravalvular leak injury to the pulmonary homograft. Two fatalities (of septicemia from urinary tract infection, and excessive vomiting and severe electrolyte imbalance from gastroenteritis) were apparently not related to the operation per se, and 2 more patients died at home 3 and 5 years after the operation without obvious causes, although they were well when last seen. One patient died of hemopericardium brought about by excessive anticoagulation, 1 patient died of congestive heart failure after myocardial infraction, and 2 patients died of late endocarditis. No autopsy could be obtained on the patient who died of congestive heart failure.

Events during follow-up that were successfully managed included 1 late wound infection, 1 late pericarditis with tamponade, 3 episodes of major arrhythmia, and 1 major paravalvular leak that was repaired.

Nine patients showed evidence of progressive autograft regurgitation and/or stenosis, developing over 2 to 5 years. In 4 of these patients, the autografts had to be explanted. Gross examination of the explants showed the valve leaflets to be thickened and retracted in some cases. There were variable degrees of calcification, but no vegetations or thrombi. Microscopically, explanted valves showed neointima formation (pannus), fibrosis, disruption of elastic fibers, and scant and focal nonspecific chronic inflammation. Active rheumatic disease was suspected in 1 valve. The 


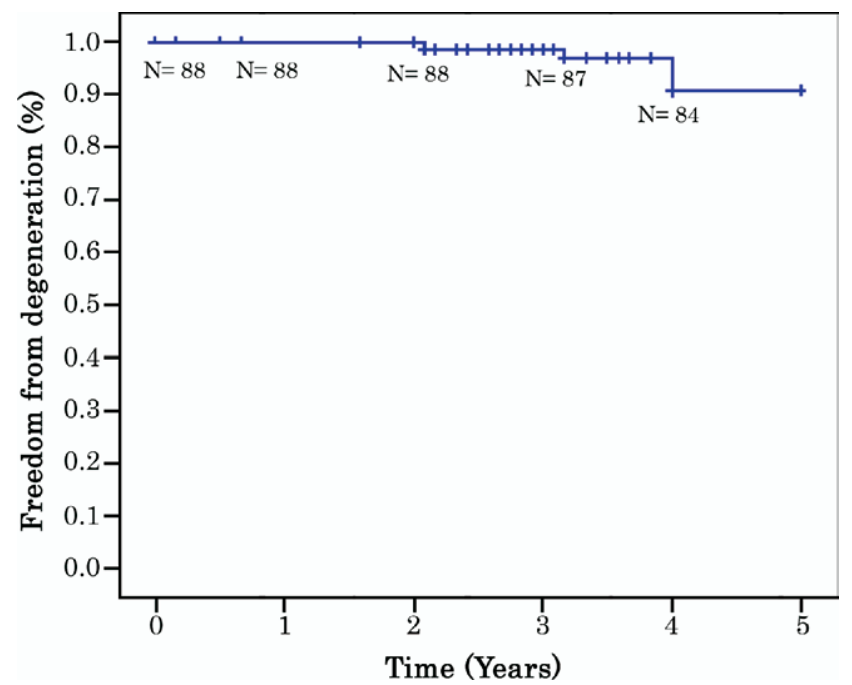

Figure 1. Actuarial freedom from valve degeneration in "successful" Ross II procedures. $\mathbf{N}=$ number of patients included in the analysis at the beginning of each year follow-up.

autograft was explanted in 1 patient because of endocarditis 3 years after the operation. There was no predilection of 1 of the 3 operative configurations to infection when compared with the others.

Various degrees of pulmonic stenosis developed in 4 patients' pulmonary xenograft (3) or homograft (1) during the follow-up period. Only 1 patient (homograft, 5 years postoperative) now has significant (gradient $>60 \mathrm{~mm} \mathrm{Hg}$ ) stenosis and is awaiting reoperation.

A review of the 64 patients who are presently being followed up (Table E4) shows that most are in sinus rhythm, not taking anticoagulants, and in New York Heart Association functional class I or II. Three patients who were in atrial fibrillation were not receiving anticoagulation because there was a contraindication for it in 1 patient (in whom a subarachnoid hemorrhage developed) and noncompliance in 2 patients. The 3 patients received antiplatelet therapy. The echocardiographic findings of the 64 patients (Table E5) are, for the most part, acceptable.

Figure 1 depicts the freedom from valve degeneration curve, estimated at $93.4 \%$ after 5 years. Figure 2 depicts the freedom from reoperation curve, estimated at $94.2 \%$ after 5 years. Figure 3 depicts the general survival (freedom from all death) curve for the series, estimated at $86.0 \%$ after 5 years. On exclusion of operative deaths, there were 2 fatalities at the end of the first year, 4 fatalities at the end of the second year, 6 fatalities at the end of the third year, 9 fatalities at the end of the fourth year, and 11 fatalities at the end of the fifth year. The 4 explant operations performed because of Dacron tubing collapse were not taken into account in our calculations because we believe this problem

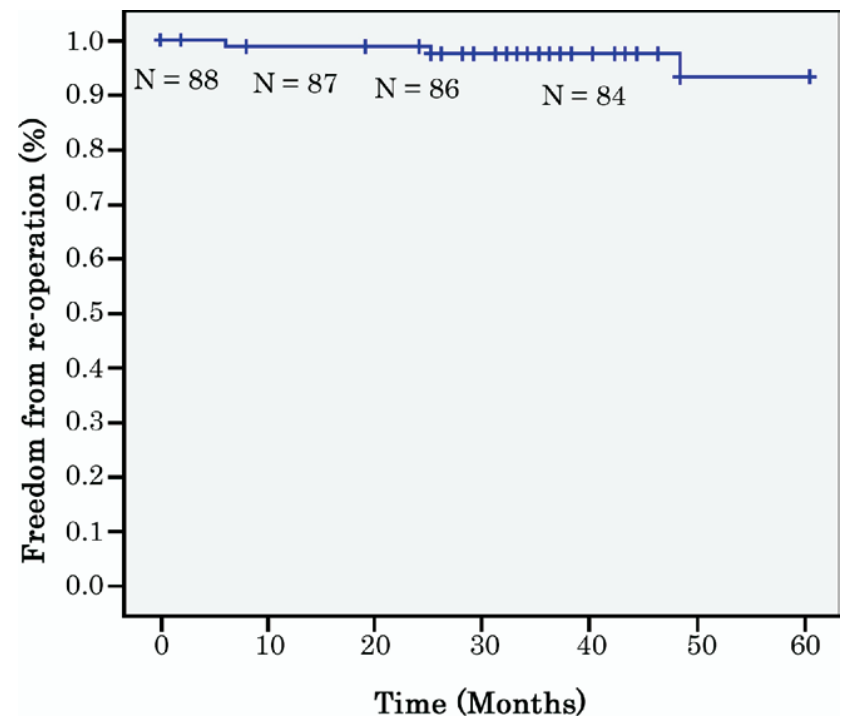

Figure 2. Actuarial freedom from reoperation in "successful" Ross II procedures. $N=$ number of patients included in the analysis at the beginning of each year follow-up.

was adequately solved and will not be a factor in future evaluations.

We found no statistically significant differences in survival, reoperation, and degeneration outcomes across age categories; however, in multiple regression analysis, after adjustment for weight, height, and echocardiogram findings,

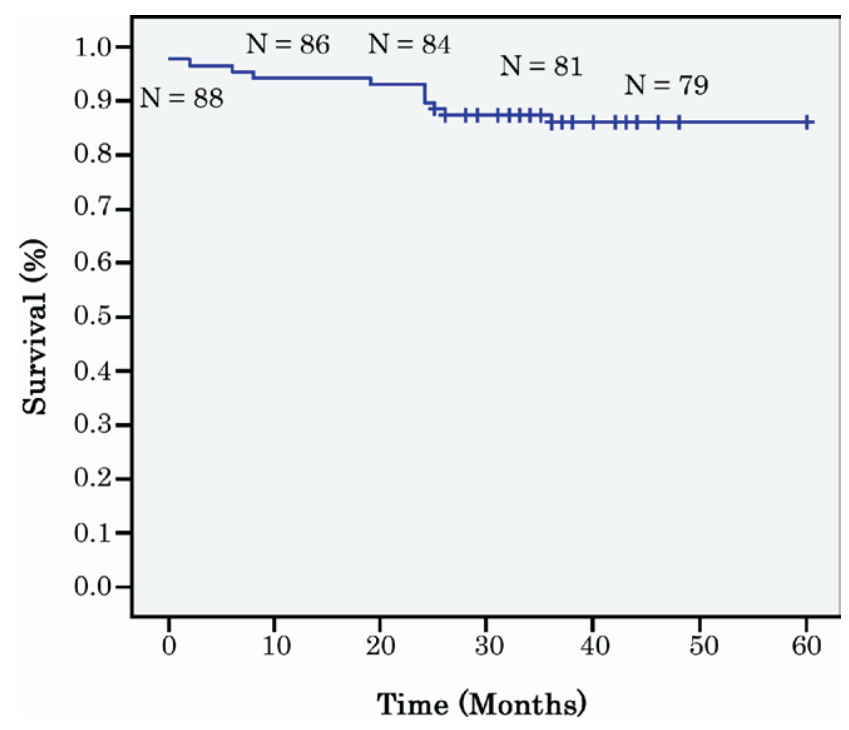

Figure 3. Actuarial survival curve in "successful" Ross II procedures. $\mathbf{N}=$ number of patients included in the analysis at the beginning of each year follow-up. 
only age showed a strong negative relation with reoperation $(P=.05)$ and mortality $(P=.02)$.

Analysis of the 3 operative techniques showed no statistically significant differences in the outcomes of death, degeneration, and reoperation. The use of BioGlue did not produce ill effects in any of the patients, and none of the patients in whom we used Bio-Glue underwent reoperation.

For the 4 patients who were lost to follow-up, the survival, degeneration, and reoperation curves show the events in all patients up to the 5-year point when the software excluded the patients lost to follow-up from the analysis.

\section{Discussion}

The fact that an ideal mitral substitute has so far eluded cardiac surgeons should not deter us from continued efforts to solve this international problem. ${ }^{11}$ There is no question that if mitral pathology can be corrected with reconstructive surgery, that option should be exercised, even if the pathology is rheumatic; for there is no mitral valve better than one's own. Not every valve, however, can be repaired, and oftentimes a patient with a reconstructed rheumatic valve returns with a failed repair caused by recurrent rheumatic activity. Choosing the right mitral substitute for a particular patient is one of the most difficult decisions a cardiac surgeon working in a developing country has to make. In many of those countries proper anticoagulation is almost an impossibility, ${ }^{12}$ which makes mechanical prostheses, durable as they are, undesirable. In regard to tissue options, mitral homografts are not used by their original proponents because of lack of durability, ${ }^{13}$ and although the results of the quadrileaflet bovine valve (Quattro, St Jude Medical Inc, Minneapolis, Minn) are good at midterm, ${ }^{14}$ it is still not commercially available.

Stented bioprostheses have not demonstrated sufficient durability in young patients. ${ }^{15}$ Although the new generations of bioprostheses have fared much better, they start to degenerate quickly after their fifth year, especially in young patients. ${ }^{16-18}$ A comparison of our results with the results of second-generation bioprostheses (eg, Carpentier-Edwards supra-annular porcine [Edwards Lifesciences, Irvine, Calif], Carpentier-Edwards Perimount pericardial [Edwards Lifesciences], Hancock II bioprosthesis [Medtronic, Inc, Minneapolis, Minn], and Biocor porcine bioprosthesis [St Jude Medical, St Paul, Minn]) failed to show a statistical difference in survival or structural valve deterioration at 5 years. However, because the mitral-pulmonary autograft is made of viable autogenic tissue, we expect that it will be more durable in the long run and be comparable to the pulmonary autograft in the aortic position. Some of the early autografts implanted by Ross ${ }^{19}$ were functioning well 11 to 15 years after the initial operation.
Comparison of our reoperation (Figure E4) and survival (Figure E5) curves with those of the Ross registry (www. rossregistry.com) showed no statistically significant difference in either case.

Rheumatic heart disease is still rampant in many parts of the world and does not seem to be abating anytime soon. ${ }^{20}$ Children, young adults, and expectant mothers who need their mitral valves replaced are entitled to an option better than the mechanical valve, with its inherent thromboembolic risks and required taxing and relatively expensive lifelong anticoagulation, and the available biologic valves, with their insufficient long-term durability.

There have been some reservations with regard to using the Ross procedure in patients with rheumatic mitral disease. ${ }^{21,22}$ However, Al-Halees and colleagues ${ }^{21}$ concluded that it was inadvisable to offer the Ross operation to rheumatic patients with dilated aortic roots $(\geq 28 \mathrm{~mm}$ ) or to patients with concomitant mitral valve disease. ${ }^{21}$ Kumar and colleagues ${ }^{22}$ added the factor of age ( $<30$ years), but this seems to be a point of contention (see "Discussion" in Kumar and colleagues' article). Despite the rheumatic cause, we believe that young rheumatic patients deserve the benefit of the Ross II operation, because the alternative (mechanical or bioprosthetic mitral replacement) is not entirely satisfactory.

Although approximately half of the patients with mitral disease have concomitant atrial fibrillation, we should not accept a mechanical option because the risk of thromboembolism is much higher from the mechanical prosthesis than from lone atrial fibrillation, and there are fairly effective methods of atrial fibrillation ablation currently available.

The pulmonary autograft has unique salutary features, chief among which is its viability and nonthrombogenicity. Its stentless design also keeps mitral gradients at a minimum and accommodates the mitral annulus in the changes of the cardiac cycle. Its ability to grow with the child is yet to be proven, as well as its long-term durability, both of which need longer follow-ups.

We believe that there is a place for the mitral pulmonary autograft in the cardiac surgeon's armamentarium. We see a clear benefit for it in the difficult congenital mitral lesion that cannot be repaired ${ }^{23}$ and in those patients who cannot take anticoagulants and have a long life expectancy ahead of them. It should be seriously considered in developing areas of the world where lifelong anticoagulation is not practical but where pulmonary homografts can somehow be obtained. It is unfortunate that only a few teams in the world have been willing to adopt the procedure. ${ }^{6,20,23-26}$

We think the best candidates for the Ross II operation are those who are in sinus rhythm, are aged less than 50 years, have a large enough left atrium $(>5 \mathrm{~cm})$, and have no important comorbid conditions. 


\section{References}

1. Kabbani SS, Ross DN, Jamil H, et al. Mitral valve replacement with pulmonary autograft- initial experience. J Heart Valve Dis. 1999;8: 359-67.

2. Kouchoukos NT, Masetti P, Nickerson NJ, et al. The Ross procedure: long-term clinical and echocardiographic follow-up. Ann Thorac Surg. 2004;78:773-81.

3. Carpentier A. Cardiac valve surgery-the "French correction." J Thorac Cardiovasc Surg. 1983;86:323-37.

4. Kabbani SS, Jamil H, Hammoud A. Technique for replacing the mitral valve with a pulmonary autograft: the Ross-Kabbani operation. Ann Thorac Surg. 2001;72:947-50.

5. Kabbani S, Jamil H, Murad GH, Hamzeh KH, Sabbagh A. Ablation of atrial fibrillation using microwave energy-early experience. Asian Cardiovasc Thorac Ann. 2005;13:247-50.

6. Hubka M, Siska K, Holec V. Replacement of the mitral valve with an aortic valve homograft implanted into the left atrium. J Thorac Cardiovasc Surg. 1967;53:260-7.

7. Kabbani SS, Jamil H, Hammoud A, Nabhani F, Hariri R, Sabbagh N. The mitral pulmonary-autograft: a follow-up cautionary report. J Heart Valve Dis. 2000;9:801-4.

8. Kabbani S, Jamil H, Hammoud A, et al. Use of the pulmonary autograft for mitral replacement-short and medium-term experience. Eur J Cardiothorac Surg. 2001;20:257-61.

9. Kabbani S, Jamil H, Hammoud A, et al. The mitral pulmonaryautograft: assessment at midterm. Ann Thorac Surg. 2004;78:60-5.

10. Yacoub MH, Kittle CF. A new technique for replacement of the mitral valve by a semilunar valve homograft. $J$ Thorac Cardiovasc Surg. 1969;58:859-69.

11. Kabbani SS. Editorial: is an optimal mitral substitute within reach? Ann Thorac Surg. 2000;69:1651-2.

12. Kabbani S. Is it time to look for an alternative? Asian Cardiovasc Thorac Ann. 2001;9:79-81.

13. Chauvaud S, Waldmann T, d'Attellis N, et al. Homograft replacement of the mitral valve in young recipients: mid-term results. Eur J Cardiothorac Surg. 2003;23:560-6.

14. Mohr FW, Lehmann S, Falk V, et al. Clinical experience with stentless mitral valve replacement. Ann Thorac Surg. 2005;79:772-5.

15. Antunes MJ, Med M, Santos LP. Performance of glutaraldehydepreserved porcine bioprosthesis as a mitral valve substitute in a young population group. Ann Thorac Surg. 1984;37:387.

16. Jamieson E, Marchand M, Pelletier C, et al. Structural valve deterioration in mitral replacement surgery: comparison of Carpentier-Edwards supra-annular porcine and Perimount pericardial bioprostheses. J Thorac Cardiovasc Surg. 1999;118:297-305.

17. Borger MA, Ivanov J, Armstrong S, Christie-Hrybinsky D, Fiendel CM, David TE. Twenty-year results of the Hancock II bioprosthesis. J Heart Valve Dis. 2006;15:49-56.

18. Kirali K, Güler M, Tuncer A, et al. Fifteen-year clinical experience with the Biocor porcine bioprostheses in the mitral position. Ann Thorac Surg. 2001;71:811-5.

19. Ross DN, Kabbani S. Mitral valve replacement with a pulmonary autograft: the mitral top hat. J Heart Valve Dis. 1997;6:542-5.

20. Steer AC, Carapetis JR, Nolan RM, Shann F. Systematic review of rheumatic heart disease prevalence in children in developing countries: the role of environmental factors. J Paediatr Child Health. 2002;38: 229-34.

21. Al-Halees Z, Pieters F, Qadoura F, Shahid M, Al-Amri M, Al-Fadley F. The Ross procedure is the procedure of choice for congenital aortic valve disease. J Thorac Cardiovasc Surg. 2002;123:437-42.

22. Kumar A, Talwar S, Saxena A, Singh R. Ross procedure in rheumatic aortic valve disease. Eur J Cardiothorac Surg. 2006;29:156-61.

23. Frigiola A, Badia T, Ponie G, et al. Pulmonary autograft for mitral valve replacement in infants: the Ross-Kabbani operation. Ann Thorac Surg. 2005;79:2150-1.

24. Kumar AS, Aggarwal S, Choudhary SK. Mitral valve replacement with the pulmonary autograft: the Ross II procedure. J Thorac Cardiovasc Surg. 2001;122:378-9.

25. Brown JW, Ruzmetov M, Turrentive MW, Rodefeld MD. Mitral valve replacement with the pulmonary autograft: Ross II procedure with
Kabanni modification. Semin Thorac Cardiovasc Surg Pediatr Card Surg Annu. 2004;7:107-14.

26. Athanasiou T, Cherian A, Ross D. The Ross II procedure: pulmonary autograft in the mitral position. Ann Thorac Surg. 2004;78:1489-95.

\section{Discussion}

Dr J. Brown (Indianapolis, Ind): Your experience with this operation is clearly the largest and the best in the world. Mr Ross, who is credited with this operation, did the autograft replacement of the mitral valve in 8 patients before the 2 of you collaborated, and then you have continued to modify his technique to make it simpler and more reproducible. The pulmonary autograft has been used in thousands of patients in the aortic valve position but in less than 150 patients in the mitral position. The autograft is the only potential durable bioprosthetic valve that is available for the mitral position. As a congenital heart surgeon, I use this operation for a select group of patients who cannot be treated with other alternatives. We have had excellent results in our small series of 8 patients with the pulmonary autograft, except in 2 or 3 patients in whom unacceptable mitral regurgitation developed because 1 of the leaflets stretched.

Do you aggressively treat systemic hypertension in your patients postoperatively to prevent stretching of the pulmonary autograft leaflets until they adapt to left ventricular systolic pressure? What is your graft material of choice to support your autograft? The woven Dacron graft that we have used in the United States has recently been discontinued. So we are looking for a woven graft that is stiff enough. How would you select the graft size? Do you use preoperative echo? And if you do use preoperative echo, how much larger a graft do you select than the echo diameter of the pulmonary autograft? And fourth, have the 2 children who underwent this technique and had the grafts split shown evidence of growth of their autograft?

Dr Kabbani: Yours has been one of the few teams who have picked up this procedure and have been supportive of our endeavor all along.

We have had no problem with the pulmonary hypertensive patients. For some reason after the operation, after any operation, on a stenotic valve, the pulmonary pressure just decreases, and we have not had any reason to deal with these patients in a special way.

As far as the graft material is concerned, we have used Dacron. As you say, when we started using the newer soft variety, we had this problem, and we reverted to autoclaving the material with albumin, hoping to get some resilience; however, in another 2 patients the problem recurred, probably because the albumin was washed away with warm blood. So now what we are doing is very secure, and that is using BioGlue between the pericardium sleeve and the Dacron material. This makes the substance of the conduit quite firm, and we have had no problem since.

In regard to the sizing of the graft, we take the eyeball sizing of the pulmonary artery and we take a size that is just slightly larger than that. We have had no problem with the sizing at all, and this is one thing that we don't have to worry about in this operation.

Of the 2 children, 1 had endocarditis and we had to explant the autograft a few years after the operation, and 1 is okay; he is in Beirut, but the family will not bring him in to have another echo so that we can know that the valve grew with the child. So I don't have an answer to your last question. 
Dr P. Granados (Malaga, Spain): Congratulations on your work, Dr Kabbani. What is the fate of the homograft in these patients, because we didn't see any data? Did you take any pharmacologic measures to prevent homograft deterioration?

Dr Kabbani: You are talking about the pulmonary homografts, the homografts in the pulmonary position? Yes, we have 4 patients who are starting to show stenosis; only 1 is critical and needs an operation, but we have not operated on any of them yet.

No, we don't give any special treatments, so far we have not done so, to prevent stenosis in the pulmonary homografts.

Dr M. del Rio (Riverside, Calif): Insofar as the autograft, I have toyed around with a hybrid valve for which one uses 2 leaflets of the pulmonary valve and retains 1 of the leaflets of the mitral valve and insets that into the mitral position. Has that ever been tried at your institution or tested in that way?

Dr Kabbani: No.

Dr del Rio: All right.

Dr J. Fragata (Lisbon, Portugal): I was always a bit reluctant to perform the Ross operation in patients with rheumatic fever or a history of rheumatic fever. Do you have any evidence or idea whether the rheumatic process can continue in the autograft valve in the mitral position and would you keep these patients on antirheumatic prophylaxis?

Do you anticoagulate these patients? When we perform a Fontan operation with a lateral tunnel, sometimes some clots go around the prosthetic tube. I know this is covered with pericardium, but don't you get any clots around the tube in the floor of the atrium, around the annulus of the mitral valve?
Dr Kabbani: The first question was regarding rheumatic activity, and we expect that what we will have with the mitral pulmonary autograft is similar to what was experienced by those who did the classic Ross in the aortic position. Dr Al-Halees from Saudi Arabia reported in his rheumatic series that approximately $10 \%$ of his patients had rheumatic activity in the autograft. There was only 1 patient in whom we suspected that there was rheumatic involvement in the pathology, but that was all in this series.

As for the second question, you are right, theoretically you might have clots in that area between the autograft and the left atrium, but we have had no problem from there. We anticoagulate these patients for 3 months for a start, and then we stop if the patient is in sinus rhythm. We anticoagulate them if they are in atrial fibrillation for an international normalized ratio of 2 or 2.5 .

Dr S. Yassin (Albuquerque, NM): How do you address the 4 patients in whom the autograft had to be sacrificed?

Dr Kabbani: I am sorry, I don't understand the question.

Dr Yassin: You mentioned there were 4 patients in whom the autograft could not be used. How did you address those patients?

Dr Kabbani: What did I do?

Dr Yassin: Yes.

Dr Kabbani: We just used a mechanical prosthesis instead. We explanted them because there was a bent conduit causing obstruction. In 2 patients, we could do something about it; I don't want to take the time of the audience, but the 4 that we sacrificed were replaced with a mechanical prosthesis. 


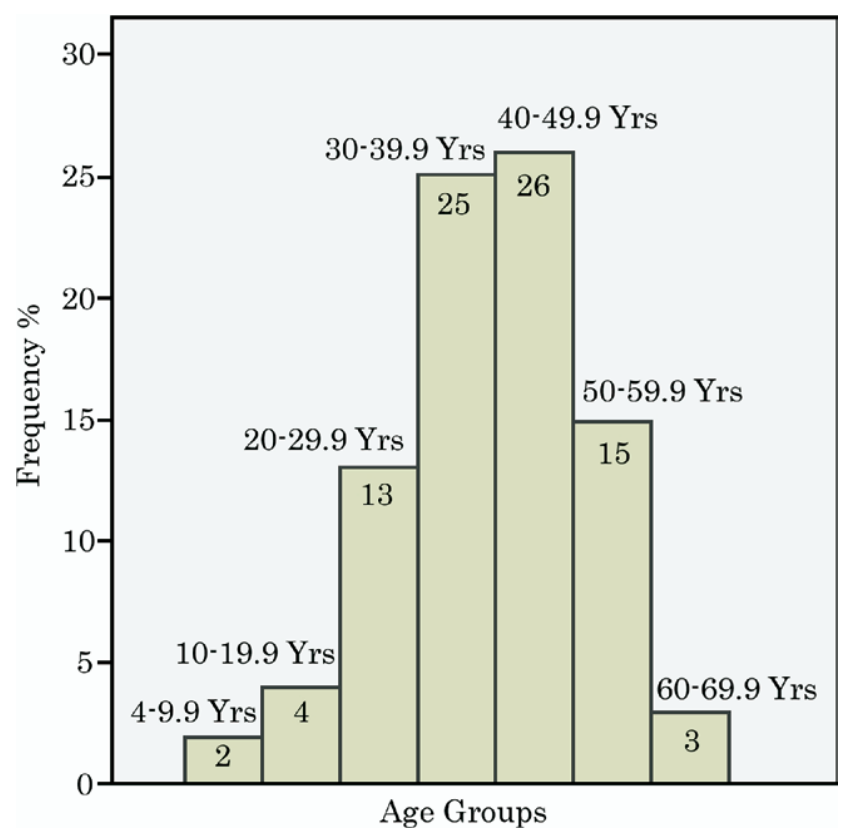

Figure E1. Distribution of patients according to 10 -year age groups; the total number of patients and percentages in each age group are presented. 

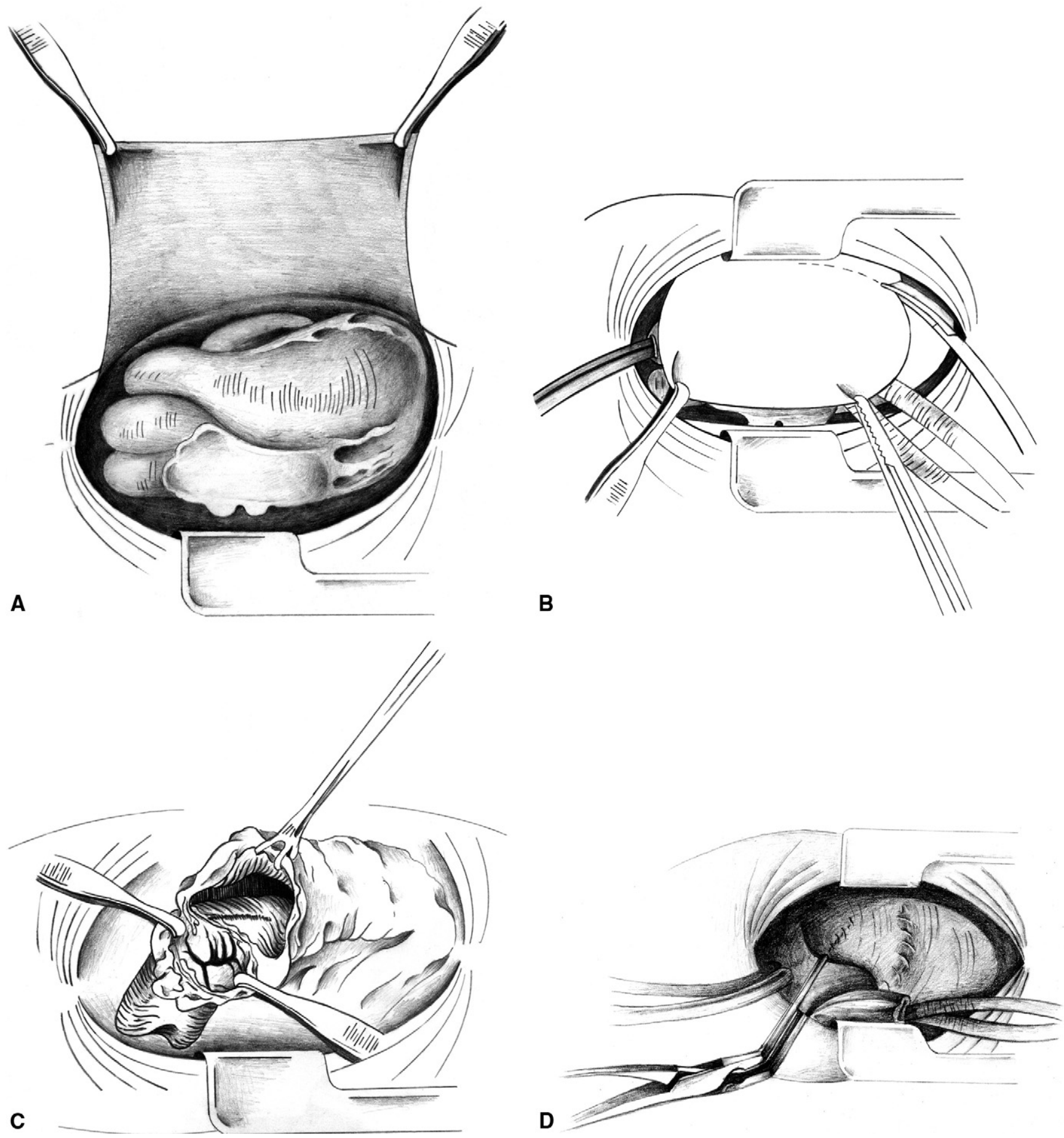

Figure E2. Stages of operation. A, Flap of pericardium $10 \mathrm{~cm}$ long is created and left hanging until a decision is made to perform operation. $B$, If mitral reconstruction is impossible and a Ross II operation is decided on, a $10 \times$ $4 \mathrm{~cm}$ of pericardium (in the adult patient) is excised. C, Pulmonary autograft is taken down as in the classic Ross operation. D, Pulmonary substitute (preferably a pulmonary homograft) is interposed. E, A 2.5-cm piece from a crimped woven (preferably rigid) Dacron tubing (usually $30 \mathrm{~mm}$ in diameter) is cut off and marked at both ends with 6 equidistant points, starting with the prefabricated line. F, Pericardial strip is wrapped around the Dacron tubing (smooth surface out), and an adhesive glue is applied to its inner surface. G, Excess pericardium is cut off to adjust the length and height of the pericardial strip to the Dacron tubing. $H$, Autograft is cleaned of fatty tissue and trimmed down to $2 \mathrm{~mm}$ beyond the commissures distally and down to $2 \mathrm{~mm}$ of ventricular muscle proximally. 

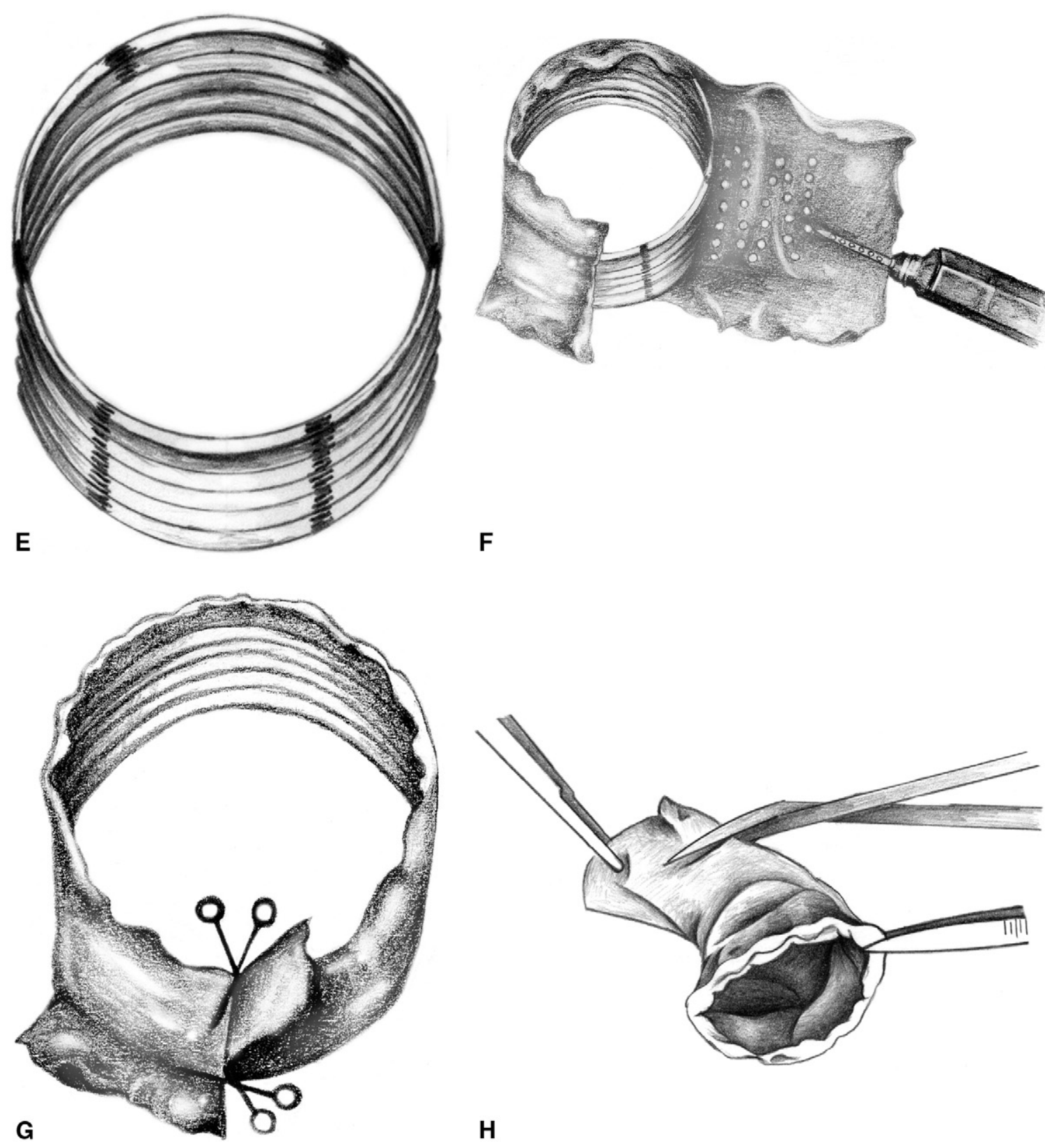

F

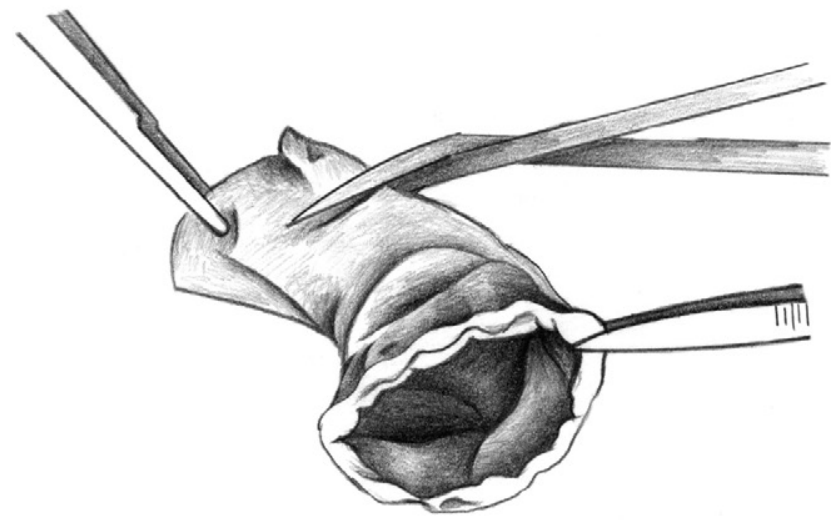

H

Figure E2. (Continued) 

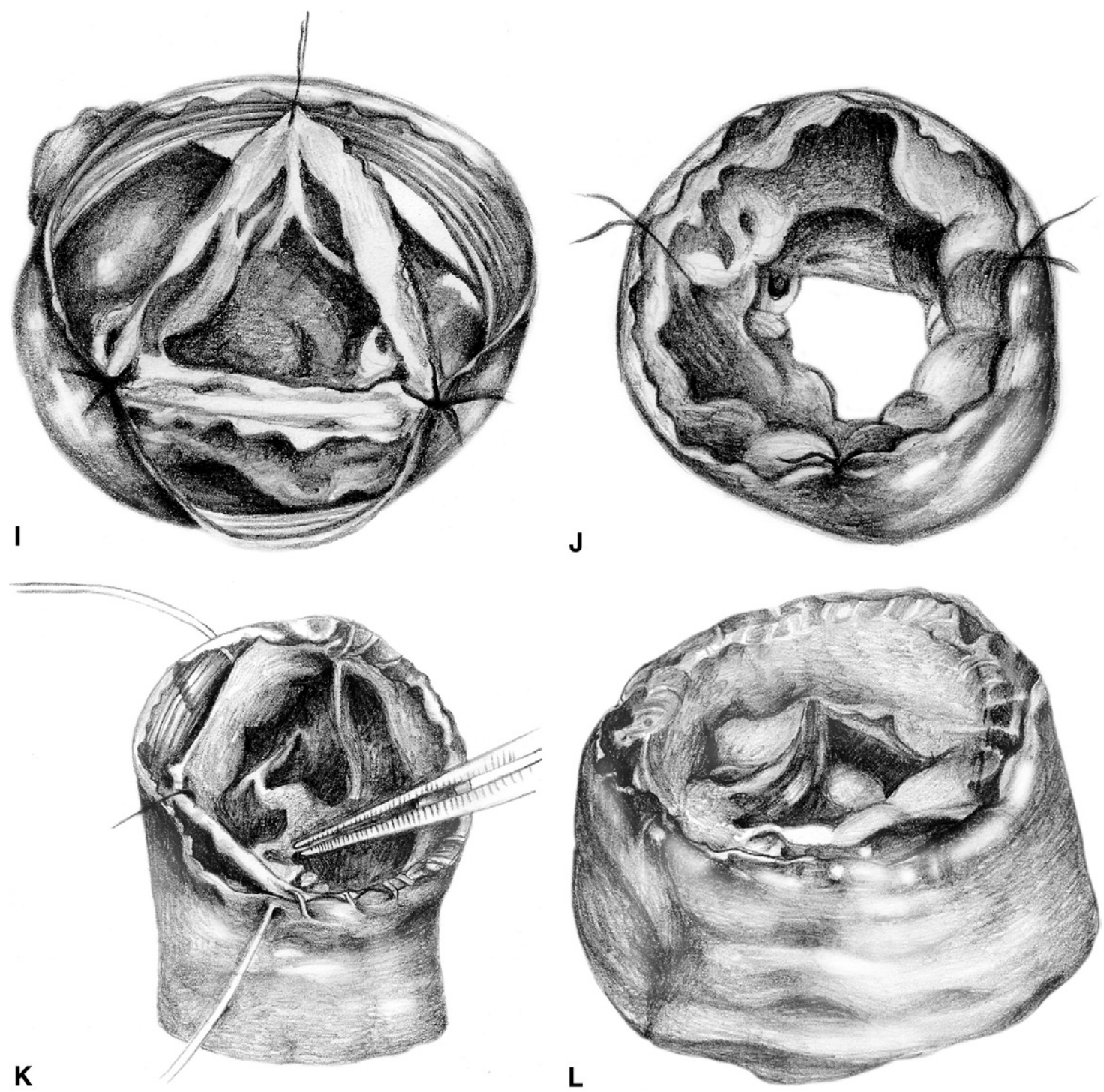

Figure E2. I, Prepared autograft is inserted within the Dacron tubing, and its distal (pulmonary) end is anchored to the Dacron pericardial tube with 3 temporary 4-0 polypropylene sutures. J, Similar procedure is done with the proximal (ventricular) end of the autograft. K, A 5-0 polytetrafluorethylene running stitch is applied distally joining the autograft and Dacron/pericardial conduit, removing stay sutures as they are reached. $L$, Distal running suture is complete. A similar procedure is carried out proximally, in effect completing the preparation of the conduit and covering all Dacron material. M, Distal end of the prepared conduit is sutured to the annulus of the excised mitral valve after preserving the subvalvular apparatus as much as possible, applying some form of atrial fibrillation ablation if necessary, and excluding the left atrial appendage. $N$, Schematic profile of the operation. 

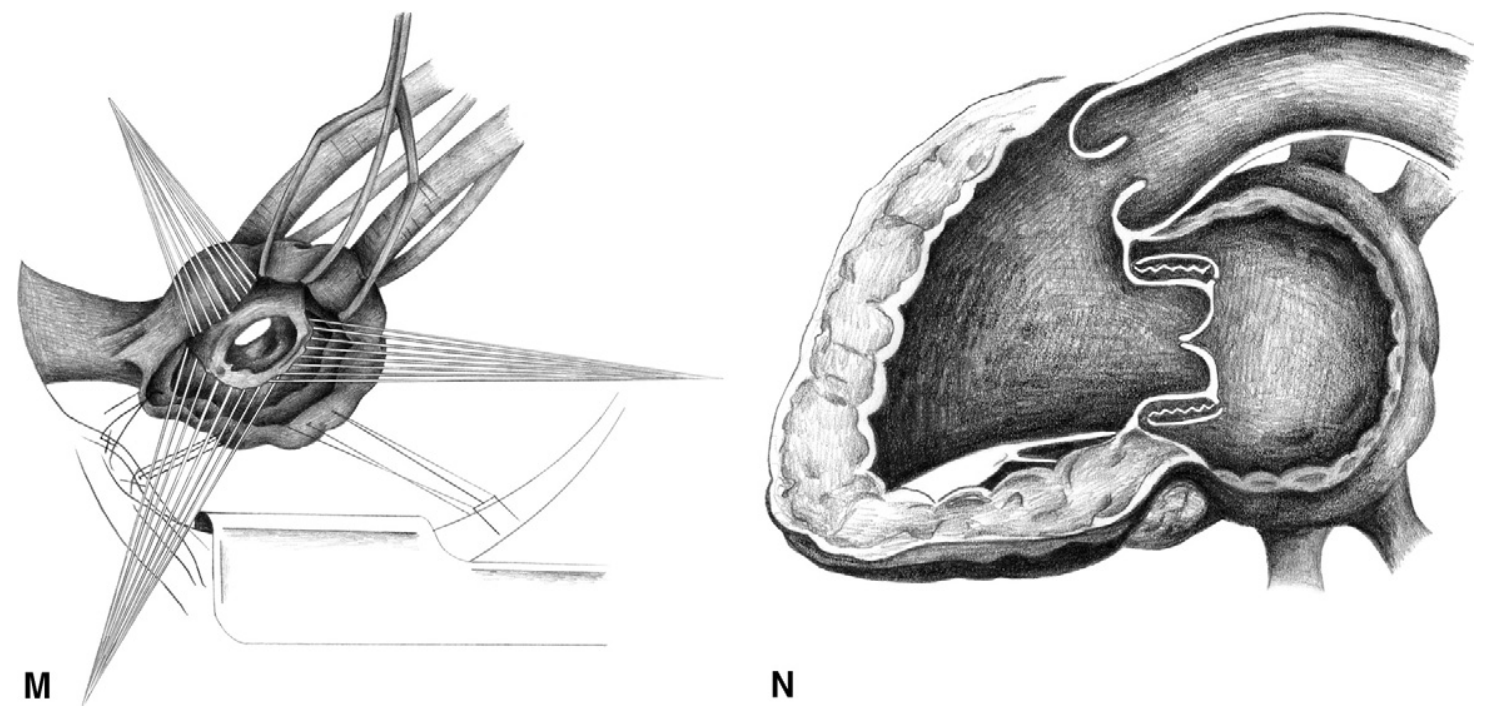

$\mathbf{N}$

Figure E2. (Continued)
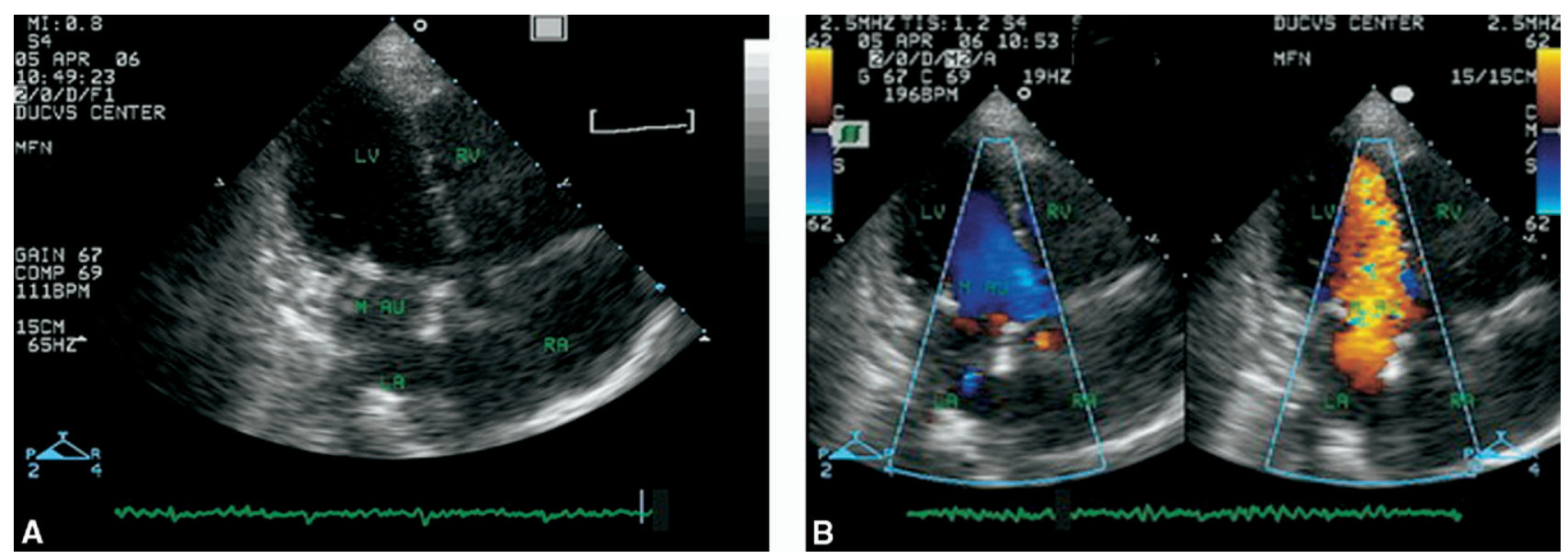

Figure E3. A, Postoperative 4-chamber view echocardiogram of the autograft/Dacron conduit. B, Two-dimensional echocardiogram with color Doppler during systole and diastole. 


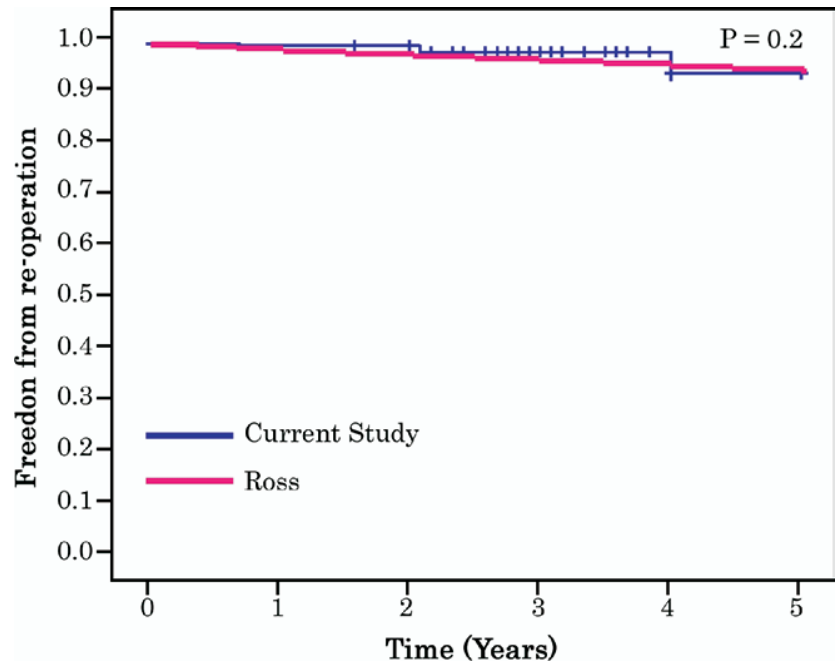

Figure E4. Comparative actuarial curves for freedom from reoperation.

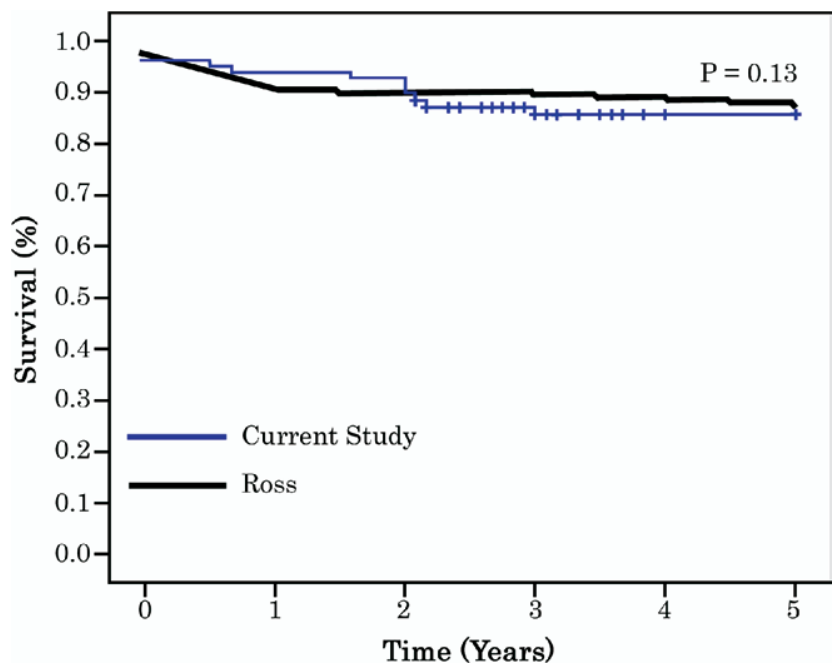

Figure E5. Comparative actuarial survival curves. 
TABLE E1. Preoperative data: Clinical presentation

\begin{tabular}{|c|c|c|}
\hline & & No. of patients \\
\hline NYHA I & & 3 \\
\hline NYHA II & & 39 \\
\hline NYHA III & & 42 \\
\hline NYHA IV & & 4 \\
\hline Total & & 88 \\
\hline \multicolumn{3}{|c|}{ Echo/Doppler data } \\
\hline $\begin{array}{l}\text { Significant leaflet } \\
\text { calcification }\end{array}$ & 37 patients & Mean \\
\hline EF & $46 \%-84 \%$ & $60.15 \pm 15.45$ \\
\hline $\begin{array}{l}\text { Estimated PA } \\
\text { systolic pressure }\end{array}$ & 27-90 mm Hg & $46.65 \pm 13$ \\
\hline LA & $3.5-9.2 \mathrm{~cm}$ & $6.03 \pm 1.5$ \\
\hline MVA (for MS) & $0.5-1.9 \mathrm{~cm}^{2}$ & $1.14 \pm 0.4 \mathrm{~cm}^{2}$ \\
\hline
\end{tabular}

NYHA, New York Heart Association; $E F$, ejection fraction; $P A$, pulmonary artery; $L A$, left atrium; $M V A$, mitral valve area; $M S$, mitral stenosis.

TABLE E2. Operative data

\begin{tabular}{|c|c|c|}
\hline \multicolumn{3}{|c|}{ No. of patients } \\
\hline Transseptal approach & 33 & \\
\hline Standard left atriotomy & 55 & \\
\hline \multicolumn{3}{|l|}{ RVO reconstructed with: } \\
\hline Pulmonary homograft & 29 & \\
\hline Pulmonary xenograft & 56 & Size: $21-30$ (mean 25) \\
\hline Aortic homograft & 3 & \\
\hline Tricuspid annuloplasty & 26 & \\
\hline $\begin{array}{l}\text { AF ablation therapy with } \\
\text { microwave }\end{array}$ & 11 & \\
\hline Pericardial sleeve & 46 & \\
\hline "Top-hat" configuration & 36 & \\
\hline "Mini-skirt" configuration & 10 & \\
\hline Free Dacron tubing & 42 & \\
\hline Aortic crossclamp time & & $\begin{array}{l}92-275 \text { min (mean } \\
124.97 \pm 34 \mathrm{~min})\end{array}$ \\
\hline
\end{tabular}

$R V O$, Right ventricular outflow; $A F$, atrial fibrillation.
TABLE E3. Echo/Doppler data on discharge from hospital

\begin{tabular}{lc}
\hline MVA & $\begin{array}{c}1.8-4.9 \mathrm{~cm}^{2} \\
\text { (mean 2.97 } \pm 0.53)\end{array}$ \\
Mean mitral gradient & $2-9 \mathrm{~mm} \mathrm{Hg}$ \\
& (mean $3.5 \pm 1.45)$ \\
PA systolic pressure & $12-60 \mathrm{~mm} \mathrm{Hg}$ \\
& (mean 27.4 \pm 9.5$)$ \\
& No. of patients \\
Mild paravalvular leak & 3 \\
O MR & 57 \\
Trace MR & 19 \\
Mild TR & 7
\end{tabular}

MVA, Mitral valve area; $M R$, mitral regurgitation; $T R$, tricuspid regurgitation; $P A$, pulmonary artery.

TABLE E4. Review of 64 patients' follow-up

\begin{tabular}{lll}
\hline NYHA & Class: I & 44 patients \\
& Class: II & 18 patients \\
& Class: III & 2 patients \\
& Class: IV & 0 patients \\
Rhythm: & Sinus & 39 patients $(61 \%)$ \\
& AF & 25 patients \\
Anticoagulation & No & 42 patients $(66 \%)$ \\
& Yes & 22 patients
\end{tabular}

NYHA, New York Heart Association. Excluding fatalities, lost to follow-up, and explants.

TABLE E5. Review of 64 patients' echocardiograms

MVA

Mitral gradient

\section{0}

Mild

Mild to moderate

Moderate

TR

Mild

Moderate

Severe

PA systolic pressure

PA peak gradient
Mild to moderate (mean $3.05 \pm 0.51$ )

$$
- \text { median }=3
$$

(mean $5.28 \pm 1.99$ )

- median $=5$ 